ISCKMC 2020

International Scientific Congress «KNOWLEDGE, MAN AND CIVILIZATION»

\title{
CROSS-DISCIPLINARY DESIGN TECHNOLOGY USING IN FORMING OF PROJECT CULTURE OF FUTURE DESIGNERS
}

\author{
Tatyana Evgenyevna Belyakova (a)*, Oksana Sergeevna Goltsev (b), \\ Elena Vladimirovna Vasilenko (c), Pavel Gennadiyevich Vasilenko (d), \\ Konstantin Nikolaevich Shevalie (e) \\ *Corresponding author
}

\begin{abstract}
(a) Moscow State University of Technology and Management. K.G. Razumovsky (First Cossack University), 73, Zemlyanoy Val st. Moscow, evatar@list.ru,

(b) Moscow State University of Technology and Management. K.G. Razumovsky (First Cossack University), 73, Zemlyanoy Val st. Moscow, laveranta@mai.ru,

(c) Moscow State University of Technology and Management. K.G. Razumovsky (First Cossack University), 73, Zemlyanoy Val st. Moscow, elenalopasova@mail.ru,

(d) Moscow State University of Technology and Management. K.G. Razumovsky (First Cossack University), 73, Zemlyanoy Val st. Moscow, kshevale@mail.ru
\end{abstract}

\begin{abstract}
In our study the cross-disciplinary design technology was implemented on the basis of the design laboratory of the university. The organizational and functional structure of such a laboratory imitates a professional environment. From project to project students performed different roles from a design assistant in the first year at the undergraduate level to an art director at the graduate level depending on the course and level of study. A model for cross-disciplinary technology introduction has been built. It consists of the following components: subjects of design engineering (teacher, students, representatives of the target audience of a design project, external consultants and a design project owner), a target component (the goal was to develop a project culture of future designers of the corresponding level) a procedural and technological component (pre-design stage, which students go through under the guidance of teachers of general education and general professional disciplines and industrial practice), a diagnostic component (criteria, methods and means of assessment). As a result of the pedagogical experiment, the main stages of the projects development with the participation of design students of various levels of training and various profiles have been revealed with the possibility of regulating their individual educational trajectories. To track the progress of students, special maps of the project culture have been developed. At the same time, the level of the project culture development is considered achieved at one of the following levels: basic, intermediate, advanced and specialized.
\end{abstract}

2357-1330 @ 2021 Published by European Publisher.

Keywords: Cross-disciplinary, design engineering, technology, project culture 


\section{Introduction}

The process of teaching design engineering can be subordinated to a certain pedagogical technology only to a certain extent or create organizational and pedagogical conditions that will contribute to the creative activity of students. When teaching future designers, it is important to learn to separate those elements of the educational process that need to be subordinated to a clear algorithm of technology from those which should give students a certain degree of freedom. Herewith, this sphere of unlimited creativity increases with the growth of an educational level. Upon entering a university, each student is provided with a map of project culture. The map notes the level of the project culture development and an individual trajectory of the student is planned depending on this level. In other words, a student is given recommendations what role to assume and what kind of project to participate in the next module or semester (Zimnyaya, 1999).

We decided to coordinate the levels of developing the project culture with Dublin descriptors (basic, intermediate, advanced and specialized) in order to be able to use this technology in international practice. The basic level of the project culture development should be achieved by the end of the second year of the bachelor degree. Students must reach an intermediate level by the end of the third year of study, an advanced one at the stage of defending the final degree thesis on a bachelor of design, and a specialized one upon the completion of masters program. We have worked out indicators of developing the project culture of future designers at each of the listed levels according to 3 main criteria being cognitive (knowledge of what to do and how to do it), motivation-value (the degree of involvement in the design process, awareness of its importance for society) and activity (skills and abilities) ones. The assessment tools are specially developed expert questionnaires. Upon completion the design project, an expert commission consisting of university professors and representatives of employers assesses the level of project culture for each of its stages in an ideal scenario. We have identified eight stages, specifically, goal-setting, planning, pre-project analysis, development of a creative conceptual idea, preliminary design, technical design, project implementation support and conceptual foresight.

A table of characteristics was developed for typical projects of the basic, intermediate, advanced and specialized level. At the initial stage a cross-disciplinary project is assigned a status based on the characteristics listed in the table. The contribution of students participating in a project is evaluated by an expert commission at its completion. The commission makes a conclusion whether the student has mastered all the necessary components of the project culture at a certain level. If the conclusion is positive, the level of development of the project culture (basic, intermediate, advanced and specialized) is considered achieved. We strive to offer students participation in specialized projects, that is, projects of the highest level corresponding to a graduate student. Undergraduate students in such projects perform only partial tasks at a simpler level. For this reason we can involve students of different levels of training in a complex cross-disciplinary project and evaluate the results of their participation.

Table 01 shows an example of a map demonstrating the development of the project culture of a $3 \mathrm{rd}$ year undergraduate student upon training completion. The "+" sign in the goal-setting line means that a student has not only the necessary subject experience and formed motivation for setting goals for a design project of the first level of complexity but also has a successful experience of goal-setting for such a project. 
Table 1. Map of project culture levels

\begin{tabular}{ccccc}
\hline Stage of design & \multicolumn{5}{c}{ Project culture level } \\
engineering & Basic & Intermediate & Advanced & Specialized \\
\hline Goal-setting & + & & & \\
Planning & & + & & \\
Pre-project analysis & & + & & \\
Development of a & & & \\
creative conceptual & & + & \\
idea & & & \\
Preliminary design & & & \\
Technical design & + & & \\
Project implementation & + & & \\
support & & & & \\
Conceptual foresight & + & & & \\
\hline
\end{tabular}

Having analyzed the maps of project culture development, we can state that the experience of cooperation obtained in the framework of interdisciplinary projects between the participants in project activities is a component of the social competence of an individual. As well, it provides the prospects for the social and professional becoming of a future designer through harmonious and conflict-free interaction in the social environment of professional activity. It should be noted that a modern designer must have the ability to work in a team, communicate effectively with colleagues, management and clients, interact with all participants of a professional environment along various lines of cooperation (designer - client, designer - team of workers, designer - designer, etc.).

\section{Problem Statement}

Thus, one of the main differences between design engineering as a type of activity and its ultimate goal is to consciously embody new cultural values in future designers. These values, produced by designers, become the property of society both now and in the future. Consequently, one of the most urgent tasks of modern design education is to develop future designers' project culture, which has not only an ergonomic and aesthetic but also a spiritual and moral basis (Arpentieva, 2019). Thus, the urgency of the problem of forming the cultural values of a future designer is due to the presence of a central contradiction between the labor market requirements for readiness with regards to cooperation in professional activity and the insufficient level of readiness of modern pedagogical science and practice to train such specialists. This is expressed in a system of contradictions between the following aspects:

- the importance for modern Russian society to solve the problem of training a designer capable of optimal professional tasks solution basing on the principles of business cooperation and insufficient readiness of professional education to form this experience among students;

- the need to form students' experience of cooperation, which determines the readiness of future designers for joint productive activities and insufficient development of the theoretical and methodological foundations for creating this experience among students;

- potential possibilities of cross-disciplinary design as a didactic means of forming the experience in cooperation among the students of primary vocational institutions and the lack of 
scientific substantiation of the organizational and methodological conditions for its application in solving this problem.

The presented contradictions made it possible to formulate the research problem being the development and scientific substantiation of the theoretical and methodological foundations for applying cross-disciplinary design as a means of forming the subjective experience of cooperation in design students who are in cooperation with each other at all levels of interaction and when performing different professional roles within the design laboratory. It should be noted that cooperation is understood as the joint activity of the educational process participants aimed to achieve common goals (Brushlinsky, 1992). Thus, considering the theoretical aspects of "joint activity" is very relevant for our research. It has been established that nowadays, a huge amount of psychological and pedagogical literature revealing the phenomenon of joint activity has been accumulated (Dontsov, 1977; Dowell, 1975; Johnson, 1978; Tsvetkova, 1989). At the same time, this phenomenon is very multifaceted which is justified by various perspectives on understanding this phenomenon.

As part of the study, a training course devoted to developing the subjective experience of cooperation among design students within the framework of the designated cultural values was delivered. The course included such topics as the distribution of roles between participants in project activities, the concept of cooperation as an effective form of interaction, mechanisms for building cooperation, discussion of ways to implement a design product, and others. The special course has a theoretical and practical orientation, includes lectures and practical lessons. Practical exercises are provided in the form of modeling educational situations of cooperation in project activities, which enables modeling fragments of future professional activities. The special course program consists of 2 sections and they are as follows:

- Theoretical foundations for building cooperation relations between subjects of professional activity in interdisciplinary projects implementation.

- Workshop on the formation of the subject experience of cooperation in the project activities of a future designer.

\section{Research Questions}

Cross-disciplinary design technology as a means of forming project culture of a future designer.

\section{Purpose of the Study}

The purpose of the study was to develop guidelines for the introduction of cross-disciplinary design technology, based on the introduction of a model for developing a project culture of future designers within the framework of the university's design laboratory, which contributes to developing a project culture among students. 


\section{Research Methods}

Within the framework of the study, the following methods were used: study and analysis of philosophical, psychological, pedagogical and methodological literature on the problem under study, pedagogical design and modelling, testing, questionnaire methods (questionnaires, conversation), pedagogical experiment, mathematical processing of experimental data.

\section{Findings}

The study reveals the concept of cross-disciplinary design as a pedagogical technology that forms the design culture of a future designer. We rely on the opinion of Bespalko (1989), who defines pedagogical technology as a systematic and consistent implementation of a pre-designed educational process. Following this logic, we can say that a certain pedagogical model can be generated first in the form of practical intuition or an act of pedagogical art and afterwards it can be described using the language of pedagogical technology with the objective to be used many times. Possessing pedagogical technology, a beginner teacher can feel more confident in the educational process even without a rich experience in teaching and will avoid possible mistakes and shortcomings. Of course, any educational process at the same time cannot be devoid of its individual characteristics and the need to adjust technology to specific conditions as well as elements of situational creativity. Bespalko (1989), considering pedagogical technology in the context of an integral pedagogical system and external state order, distinguishes its following components: 1) organizational form, 2) didactic process, and 3) qualifications of a teacher and an entire teaching staff.

\section{Conclusion}

In conclusion, it should be noted that the results of the pedagogical experiment made it possible to describe the process of developing a complex cross-disciplinary project from the viewpoint of the methodology for the teaching process of future designers and to give methodological recommendations. In addition it helped to test the indicators of developing the project culture of future designers at each of the listed levels according to 3 main criteria, specifically, cognitive (knowledge of what to do and how to do it), motivation-value (the degree of involvement in the design process, awareness of its importance for society) and activity (skills and abilities) ones. The assessment tools are specially developed expert questionnaires. Thus, the expert questionnaires, study situations and tasks developed by us as well as the consideration and integration of methods, techniques and forms of organizing cross-disciplinary design in cooperation of all participants in project activities ensure the integrity and unity of the educational process, which determines the development of a designer's project culture, which is confirmed by the results of the experimental work. 


\section{References}

Arpentieva, M. R. (2019). Design in psychological and pedagogical design. Ergo design. https://cyberleninka.ru/article/n/dizayn-v-psihologo-pedagogicheskom-proektirovanii

Bespalko, V. P. (1989). Modern pedagogical technologies. Education.

Brushlinsky, A. (1992). The problem of the subject in psychological science. Psikhologicheskii Zhurnal, 13(6), 3-12.

Dontsov, A. M. (1977). On the problem of the integrity of the subject of collective activity. Psychology issues, 3, 25-34.

Dowell, L. J. (1975). The effects of competitive and cooperative environment on the comprehension of a cognitive task. J. Educat. Res., 68(7), 274-276.

Johnson, D. W. (1978) The effects of cooperative and individual instruction on student attitudes and achievement. J. Soc. Psychol., 104, 207-216.

Tsvetkova, T. K. (1989). A study of educational collaboration in educational psychology in the United States. Psychology issues, 2, 148-155.

Zimnyaya, I. A. (1999). Pedagogical psychology. Publishing Corporation "Logos". 